\title{
Motivation in College Student Study
}

\author{
Yujie Tang ${ }^{1, \text { a, }{ }^{*}, \dagger}$ Huilan $\mathrm{Wu}^{2, \mathrm{~b}, *, \dagger}$ Yepeng $\mathrm{Zhou}^{3, \mathrm{c}, *, \dagger}$ \\ ${ }^{1}$ Southeast University, Jiangsu, China \\ ${ }^{2}$ China University of Petroleum, Beijing, China \\ ${ }^{3}$ Shanghai Starriver Bilingual School, Shanghai, China \\ *Corresponding author.Email: ${ }^{a}$ qrq@love.com, ${ }^{b}$ author2@edu.cn, ${ }^{c}$ samuelzhou0229@gmail.com
}

${ }^{\dagger}$ These authors contributed equally.

\begin{abstract}
Nowadays, more and more people are paying much attention to the students' motivation since they have already discovered that motivation affects students' academic performance greatly. Specifically, stronger motivation leads to better academic performance and vice versa. To find out several common factors that influence students' motivation, we have researched some elements that will change students' motivation both internally and externally: schools, families, interest, self-efficacy, and perfectionism. Schools and families are environments where students grow and learn things, so they all play an important role in helping students construct strong and proper motivation. Most of the students have to find what they are interested in before deciding their study path and future career; thus, it is their obligation to figure out what they are fond of and build their self-efficacy to gain more confidence and strengthen their self-efficacy motivation. Moreover, since perfectionism is quite common among students now, people should help students establish strong and stable motivation by meeting their perfectionism requirements. Based on our result, we can finally find out the factors that influence students' motivation indeed and how we can help students reconstruct their motivation so that they can have better studying performances by teaching the educators how to use these factors and proper methods to build motivation.
\end{abstract}

Keywords: academic motivation, external factors, internal factors.

\section{INTRODUCTION}

As far as we are concerned, Grades are not the only standard to judge a student's ability. However, no one can deny that grades are the essential standard to judge a student's ability. The reasons for the differences regarding grades are naturally an inseparable topic when scores become one of the characteristics of individual differences. For this topic, motivation always holds a strong place.

Motivation is an abstract concept. Additionally, Winardi (2011) [1] indicates that our actions are often driven by the desire to achieve a certain goal. In the field of teaching, learning motivation is undoubtedly one of the basic factors that influence the way of thinking of students. Learning motivation, having a strong correlation with self-efficacy, and learning strategies, affecting students' achievement, is a fundamental factor [2]. For teachers, students' learning motivation is a complex and challenging problem they face. After all, "motivation and learning behaviour are two very important factors in determining students' learning achievement" [3].
Learning motivation is a very important variable, being the primary goal of learning [4]. Students' learning effect is related to their own learning motivation, which means that active learning motivation motivates knowledge construction; otherwise, it hinders students' learning [5].

When it comes to learning motivation, the study of internal and external factors is concrete and effective. Herath (2010) [6] believes that intrinsic and extrinsic motivations help strengthen attitudes toward behavior. Hence, this paper aims to review the theories and research related to learning motivation from internal and external aspects, including self-efficacy, the factor of family, the factor of school, and evaluation from society, to manage to sort out the framework of research this specific field. Moreover, we hope to propose a valuable direction for scholars to explore as much as possible.

\section{INTERNAL FACTORS}

Researches have shown that Interest has become one of the most important elements that influence students' studying motivation. It has already been proven that 
students' motivation has a positive relationship with their personal interests [7]: greater interests in a certain subject will positively influence students' motivation [8]. It is widely known that interest is the best teacher for students since everyone is ambitious and diligent in those fields they are fascinated with. According to Ulrich Schiefele, a number of studies are presented that indicate the importance of interest for the depth of text comprehension, the use of learning strategies, and the quality of the emotional experience while learning. This shows how important interest is to activate students' motivation in studying. Most of the students may have trouble study some subjects in which they have no interest. If they were forced to continue these subjects, they would not get an ideal result with much effort into the process. Nowadays, many teachers now notice these factors and encourage their students to find their interests during middle school time. It is beneficial for students to discover which fields they are really interested in being professional in, and it will provide students with higher study motivation.

Higher self-efficacy can help students build stronger studying motivation, according to research done by Shin (2018) [9]. It allows students to play an active role in their own learning process and finally gives the feeling of success and satisfaction. It has a strong relationship with students' motivation since students will always keep the highest ambition if they find it difficult to reach the final success. When they realize their self-efficacy, they will also be able to understand what studying efficiency they can reach. To clarify the actual relationship between students' motivation and self-efficacy, the Graduate School of IKIP Mataram has done research that results in a positive relationship between students' motivation and self-efficacy. Thus, it provides the educators an indispensable teaching method to encourage their students to study better: help students build confidence to make them believe they can study well in all fields. Also, they can always say to themselves for students themselves: I am up to the standard to do that; there is no doubt that I will reach success. According to Bandura's theory, students will definitely have a stronger motivation then, which can lead to better academic performance.

\section{EXTERNAL FACTORS}

Among external factors, some scholars have explored the study motivation of students in the course of Engineering Economics and found the key role of ability pursuit in students' study motivation. Ability pursuit and students' harvest after study this course are the key factors to stimulate study motivation. Whether the mastery of this skill can make students more competitive in the job market is the fundamental reason for study. Especially for some professional courses, they will be the main job of students after employment and the symbol of competitiveness. In addition, these scholars have made the interaction mechanism between ability pursuit, altruistic orientation, acquisition and interest in knowledge, then concluded that the path coefficient between ability pursuit and interest in study reached 0.943 , and that ability pursuit is the key factor of study motivation[10].

Award for achievements can trigger students' higher study motivation. Sometimes parents and schools will award those students who get great improvements or achieve their studying goals, which can help students improve their motivation in order to get not only satisfying academic performance but also the award. No matter which kind of award people provide, physical or spiritual, students will always be inspired with enthusiasm. For those students who get the awards, they believe the awards are like a prove of the effort and time they put into study, and they can get both mental relief and encouragement for further study; while for those students who do not get those award, some of them may be disappointed, but the others will be inspired too. They will either jealous of award of their peers' and want to chase them academically; thus, their motivation for studying can be enhanced[11]. In fact, award can be a double-edged sword to activate students studying motivation: some students may not be excited and desire the award due to the award can be invaluable, and they will not be encouraged by this way. Many schools, including elementary schools, have applied this strategy. Nearly all of them successfully activate their students studying motivation, and the study competition become more and more fierce too, which also lead to a better positive study environment.

School culture is an important factor that affects study motivation. The school's affections include school culture and teacher's and schoolmates' judge. Consistency Theory suggests that if a student fully agrees with the school value, school educational philosophy, and the school culture, if the school endorses hard work, the student's motivation to learn will also increase [12]. Based on the Consistency theory, the research shows the schoolefficacy inspires students' study motivation [13]. Another research also shows us the positive effect of the class environment on student study motivation [14]. The study found that rich teaching content, different teaching methods, and nice classes can all increase study motivation. The other important factor of schools is the teachers' judge. Teachers' judge is very important to a student since it has been proved that it has a huge influence on students' future development [15]. Some research suggested the teachers treat students in different ways by their own judge. These treats may affect students' study motivation [16]. Based on the above analysis, the school environment has large affection on study motivation.

In practical teaching problems and environments, Learning motivation is a subject of high research value. Studying students' learning motivation can effectively analyze different situations of students and provide 
specific and feasible targeted programs to promote their learning. Therefore, in this field, many scholars have carried out researches on learning motivation.

External evaluation is an indispensable environmental factor when it comes to research regarding learning motivation. This external environmental factor mainly comes from three aspects: teachers, classmates, and people's stereotypes in the social environment. The importance of teachers' words and attitudes to students' learning motivation need not be overstated. Teachers' speech and behavior, attitude, and sense of responsibility will affect students' learning motivation and psychological growth [17]. When students get positive feedback from teachers in class, such as praise, their enthusiasm for learning will naturally be higher, and they will be more willing to learn. On the contrary, if they get negative feedback, it may dampen their learning enthusiasm to some extent. In addition, peer evaluation is also an essential information channel for them to obtain learning feedback. The peer assessment approach improves students' learning achievement and enhances their self-efficacy and critical thinking tendencies [18]. At last, there are some stereotypes about majors of college students from society. The psychological and behavioral phenomena at the individual level also reflect the characteristics of the social and cultural context in which the individual lives [19]. Thus, stereotypes and evaluations in specific social contexts need to be taken into account. For example, it is widely believed that computer science and finance are more advantageous in employment, which is the stereotype offering positive feedback and can positively influence students of these majors. Nevertheless, some professional discrimination prevalent in society will bring pressure and anxiety to students, thus discouraging their learning enthusiasm.

Family affects student study motivation obviously. Some researchers have suggested that the family is a micro-system. It is an environment where the students' experience and growth. The impact on learning is a longterm and gradual process. It includes the family atmosphere and the parents' parental parenting. The family atmosphere directly affects the happiness of students and thus affects their learning motivation. Many research found the happiness, study motivation, and study stress are mutually influence. Especially in the important exam, the student needs to face the stress of family, school, and society. In this condition, the student who has good Socioeconomic status and family atmosphere can have more study motivation since most of these students are happier and less stressed [20]. On the other hand, research shows that parental parenting significantly impacts college students' learning motivation. The emotional warmth of parents is positively correlated with the intrinsic motivation and learning motivation of college students [21]. Some studies in China have shown that the average study motivation in the student group thinks their family care is higher than the average in the group, which thinks their parents do not care about them. The research found family teaching ways have a positive prediction to study motivation by regression analysis [22]. Based on the above analysis, a good family has a large effect on the study motivation.

\section{CONCLUSION}

Our study sums up the variety of factors how to affect college student study motivation with the help of some databases. This study wants to make some generalizations to help other researchers discover the objective laws that affect study motivation. We start the work by finding the external factors and internal factors. Then, we try to use existing theory to define phenomenon finding the connections within these theories. At least we found out now, the study motivation's mode of action is closely related to self-efficacy. We also find many cases which show some factors that affect study motivation. We believe they can be an assist to future researchers. But as a result of the lack of data, we cannot figure out a clear theory to explain how the study motivation runs. Our current work is based on past studies. We need more firsthand material. Maybe we need to build new research to get some special data to explore the different factors' potential connection. We guess the external factors and internal factors don't exist independently. There is an interaction between them. The external factors involved some theories like self-efficacy and consistency theory. They also apply to the role of internal factors. And just to the external factors, the environment also has the same characteristics. The family influence carries over into the school environment and vice versa. The student's natural characteristics, such as personality, can affect study motivation. So the study motivation is a complex subject. The researcher needs more data to make some specific discoveries.

\section{REFERENCES}

[1] Winardi, J. (2011). Motivation and motivating in management. Jakarta, Indonesia: Raja Grafindo Persada.

[2] Ki, S. (2020). The study of correlation between learning motivation and learning strategy -focusing on Chinese and Vietnamese learners. The Journal of Humanities and Social science, 11(4), 77-88.

[3] Jiang, Z. \& Zhou, Z. (2010). Relationships between class environment, learning self-efficacy and learning motivation of senior middle school students. Chinese Journal of Clinical Psychology, 18(6), 789791.

[4] Tokan, M. K., \& Imakulata, M. M. (2019). The effect of motivation and learning behaviour on student achievement. South African Journal of Education, 39(1), 1-8. 
[5] Kim, S. (2004). Designing a learning environment to enhance learner's interest and intrinsic motivation to learn. The Korean Journal of Educational Methodology Studies, 16(2), 39-66.

[6] Jiang Q., Liang. , Zhao. W., \& Yang, F. (2021) Research on the Motivational Structure and Behavior Path of Knowledge Construction from the Perspective of Grounded Theory. Modern Distance Education.

[7] Herath, C. S. (2010). Motivation as a potential variable to explain farmers' behavioral change in agricultural technology adoption decisions. Economic a Management, 63-71. Available at http://www.ekonomiemanagement.cz/download/133 1826748_37a6/06_herath. pdf.

[8] Müller, F. H., \& Louw, J. (2004). Learning environment, motivation and interest: Perspectives on self-determination theory. South African Journal of Psychology, 34(2), 169-190.

[9] Bye, D., Pushkar, D., \& Conway, M. (2007). Motivation, interest, and positive affect in traditional and nontraditional undergraduate students. Adult Education Quarterly, 57(2), 141-158. https://doi.org/10.1177/0741713606294235

[10] Shin, M. (2018). Effects of project-based learning on students' motivation and self-efficacy. English Teaching, 73(1), 95-114. https://doi.org/10.15858/engtea.73.1.201803.95

[11] Qi, S. J., Zhan, C. X., Zhang, Y., \& Chen, W. (2021). A study on the influence of learning motivation on learning enthusiasm and learning ability in hybrid Teaching Mode: A case study of Engineering Economics. University Education, (2), 34-38.

[12] Angrist, J., \& Lavy, V. (2009). The effects of high stakes high school achievement awards: Evidence from a randomized trial. American Economic Review, 99 (4), 1384-1414.

[13] Osgood, C. E., \& Tennenboum, G. P. H. (1955). Consistency theory

[14] Liu, Z. H. (2020). The Effect of School Identification on Students' Learning Burnout: The Mediating Effect of Learning Self-efficacy and the Moderating Effect of Learning Motivation. Journal of Nanjing University of Aeronautics and Astronautics (Social Sciences), 22(03): 114-12
[15] Zhao, B., Cai, H., Lian, R. R., \& Hu, A. Q. (2021). Classroom environment, learning motivation and learning quality of College Students. Technological wind, (06): 28-29+49.

[16] Friedrich, A., Flunger, B., Nagengast, B., Jonkmann, K., \& Trautwein, U. (2015). Pygmalion effects in the classroom: Teacher expectancy effects on students' math achievement. Contemporary Educational Psychology, 41, 1-12.

[17] Kaiser, J., Retelsdorf, J., Südkamp, A., \& Möller, J. (2013). Achievement and engagement: How student characteristics influence teacher judgments. Learning and Instruction, 28, 73-84.

[18] Chu, Y. J. (2021). The Formation and Cultivation of Learning Motivation of Japanese Majors in Universities. Heilongjiang Education (R esearch and Evaluation of Higher Education), (06): 4-6.

[19] Chang, S., Hsu, T., \& Jong, S. (2020). Integration of the peer assessment approach with a virtual reality design system for learning earth science. Computer \& Education, 146. https://doi.org/10.1016/j.compedu.2019.103758

[20] Yin, H. B. (2020). The Behavioral, Psychological and Socio-cultural Perspectives of Student Engagement Research: Perspective Shift and its Implications for Improving the Quality of Teaching and Learning in Chinese Universities. Journal of East China Nornal University (Educational Sciences), 38(11): 1-20. https://doi.org/10.16382/j.cnki.10005560.2020 .11 .001

[21] Areepattamannil, S., Freeman, J. G., \& Klinger, D. A. (2011). Influence of motivation, self-beliefs, and instructional practices on science achievement of adolescents in Canada. Social Psychology of Education, 14(2), 233-259.

[22] Hou, R. X., Duan X. M., \& Ji, F. (2011). The relations of College Students' Learning Motivation and Parental parenting. Chinese Journal of Health Psychology, 19(1): 106-107.

[23] Sun, X. C., (2020). Parents' upbringing learning motivation and autonomous learning ability in college students. Psychological Monthly, 15(18): 8588. https://doi.org/10.19738/j.cnki.psy.2020.18.034 